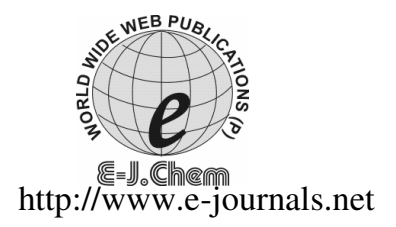

ISSN: 0973-4945; CODEN ECJHAO

E-Journal of Chemistry

2011, 8(4), 1512-1521

\title{
Evaluation of the Marine Algae Gracilaria and its Activated Carbon for the Adsorption of Ni(II) from Wastewater
}

\author{
A. ESMAEILI*, P. BEIRAMI and S. GHASEMI \\ Department of Chemical Engineering, \\ North Tehran Branch, Islamic Azad University, Tehran, Iran \\ akbaresmaeili@yahoo.com
}

Received 19 September 2010; Accepted 15 October 2010

\begin{abstract}
The batch removal of $\mathrm{Ni}^{2+}$ from aqueous solution and wastewater using marine dried (MD) red algae Gracilaria and its activated carbon (AC) was studied. For these experiments, adsorption of $\mathrm{Ni}^{2+}$ was used to form two biomasses of $\mathrm{AC}$ and $\mathrm{MD}$. Both methods used different $\mathrm{pH}$ values, biomass and initial concentration of $\mathrm{Ni}^{2+}$. Subsequently adsorption models and kinetic studies were carried out. The maximum efficiencies of $\mathrm{Ni}^{2+}$ removal were $83.55 \%$ and $99.04 \%$ for MD and AC respectively developed from it. The experimental adsorption data were fitted to the Langmuir adsorption model. The nickel(II) uptake by the biosorbents was best described by pseudo-second order rate model. The kinetic studies showed that the heavy metal uptake was observed more rapidly by the AC with compared to MD. AC method developed from MD biomass exhibited higher biosorption capacity. Adsorption capacity is related to the $\mathrm{pH}$ of solution, $\mathrm{pH} 5.0$ is optimal for nickel. The maximum efficiencies of $\mathrm{Ni}^{2+}$ removal were for $\mathrm{AC}$ method. The capacity is related to the $\mathrm{pH}$ of solution, $\mathrm{pH} 5.0$ is optimal for nickel. The equilibrium adsorption data are correlated by Langmuir isotherm equation. The adsorption kinetic data can be described by the second order kinetic models
\end{abstract}

Keywords: Biosorption, Isotherm models, Nickel, Gracilaria, Activated carbon, Wastewater, Heavy metals

\section{Introduction}

The presence of the toxic heavy metals in water resulting from rapid industrialization and technological advances is a worldwide environmental problem. Removal of these pollutants from aqueous effluents has conventionally been accomplished through abiotic processes ${ }^{1-3}$. 
However, these processes can be expensive and not fully effective. Recently, increasing interest in the application of materials of biological origin in heavy metals' removal from diluted, large volume solutions has been observed ${ }^{4-5}$. Biosorption, which uses the ability of biological materials to remove and accumulate heavy metals from aqueous solutions, has received considerable attention in recent years because of a few advantages compared to traditional methods ${ }^{6}$.

Surface adsorption is found to be an important basis for the treatment of toxic $\mathrm{Ni}^{2+}$ contaminated water ${ }^{7}$. The presence of carboxylic and sulfate groups in algae cell wall polysaccharides can act as binding sites for metals. Alginate, which is composed of mannuronic and guluronic acids, is a major polysaccharide in brown algae and acts as the source of carboxylic groups ${ }^{8}$. The cost of decontamination of toxic metals from industrial effluents and wastewaters using ion exchange resins is exorbitant. Hence, the usage of indigenous biodegradable resources for treating hazardous waste being less expensive is relevant to regional emerging environmental biotechnology9. Activated carbon has unquestionably been the most popular and widely used adsorbent in wastewater treatment employments throughout the world. However, activated carbon remains a costly material since higher the quality of activated carbon, the greater its cost. Therefore, searching of a low cost activated carbon and other adsorbent materials for the wastewater treatment is of great importance ${ }^{10-12}$. The purpose of the present study is to evaluate the biosorption capacity of the MD red algae Gracilaria in comparison with an AC from red algae Gracilaria for the removal of $\mathrm{Ni}^{+2}$ from aqueous solution, natural sea water and synthetic sea water.

\section{Experimental}

Batch equilibrium adsorption experiments were carried out in Erlenmeyer flasks in a rotary shaker for $\mathrm{AC}$ and glass column for MD. These experiments were done from aqueous solutions of initial concentrations ranged from (30-70 $\left.\mathrm{mg} \mathrm{L}^{-1}\right)$ for $\mathrm{AC}$ and $\mathrm{MD}$ using $\mathrm{pH}$ 5.0.

\section{Preparation of biomass}

Gracilaria was collected from the Persian Gulf on Qeshm Island, Iran. Before use, it was washed several times with tap water to remove the sand particles and salts. It was then sun dried for 6 days. Dry biomass was chopped, milled (size fraction of 0.5-1 $\mathrm{mm}$ ) and then used for adsorption experiments.

\section{$A C$ and MD preparation}

AC preparation: The dried red algae Gracilaria $120 \mathrm{~g}$ were added in a small portion to 96 $\mathrm{mL}$ of $97 \% \mathrm{H}_{2} \mathrm{SO}_{4}$. The resulting mixture was kept for $24 \mathrm{~h}$ at room temperature followed by refluxing in fume hood for $4 \mathrm{~h}$. After cooling, reaction mixture was washed repeatedly with deionized water and soaked in $2 \% \mathrm{NaHCO}_{3}$ solution to remove any remaining acid and $\mathrm{pH}$ of the activated carbon reached 7 , dried in an oven at $150{ }^{\circ} \mathrm{C}$ for $48 \mathrm{~h}$ and the activation temperature and activation time were selected based on the preliminary studies at different temperatures and activation time that gives maximum sorption capacity for methylene blue removal. The activated materials were then powdered using a domestic Sumeet mixie. The powdered materials were then used as adsorbents for the study. The powdered materials were then sieved and the particle size in the range of $0.3 \mathrm{~mm}$ to $1 \mathrm{~mm}$ was used and kept in a glass bottle until used. MD Preparation: The samples were then grounded to an average particle size of $0.5-1 \mathrm{~mm}^{13}$. The tests were carried out at the chemical laboratory of the Islamic Azad University, North Tehran Branch from April to May 2007. 


\section{Determination of the nickel contents}

The concentration of nickel in the solution before and after the equilibrium was determined by atomic absorption spectrometry (AAS, GBC-932), using a Perkin -Elmer analyst 300 atomic absorption spectrometer equipped with deuterium as background corrector, an airacetylene burner and controlled by IBM personal computer. The hollow cathode lamp was operated at $15 \mathrm{~mA}$ and the analytical wavelength was set at $324.8 \mathrm{~nm}$.

\section{Chemicals}

The synthetics solutions were all prepared by using deionized water and analytical graded salts of $\mathrm{NiCl}_{2} 6 \mathrm{H}_{2} \mathrm{O}$ (Merck supplied). Adsorption equilibrium isotherm was studied using MD red algae and its AC dosages of $2.5 \mathrm{~g}$ and $0.6 \mathrm{~g}$, respectively, per $30 \mathrm{~mL}$ of aqueous $\mathrm{Ni}^{2+}$ solutions of initial concentrations ranged from 30 to $70 \mathrm{ppm}$ for adsorbents using initial $\mathrm{pH}$ 5.0. All the adsorption experiments were carried out at room temperature $\left(23 \pm 2{ }^{\circ} \mathrm{C}\right)$. The $\mathrm{pH}$ of sample solution was adjusted with $1 \mathrm{M} \mathrm{HCl}$ or $1 \mathrm{M} \mathrm{NaOH}$ during the equilibrium period, at the obtained optimal values for heavy metal using agitation speed $(200 \mathrm{rpm})$ for $2 \mathrm{~h}$. Then the solution was filtered and filtrate was measured for ion content $\left(\mathrm{C}_{\mathrm{e}}\right)$ by an atomic adsorption spectroscopy (GBC-932).

\section{Adsorption studies}

The effect of $\mathrm{pH}$ on the equilibrium adsorption was investigated by using different initial concentration of $\mathrm{Ni}^{2+}\left(10 \mathrm{mg} \mathrm{L}^{-1}\right)$ and different activated carbon dosages. The $\mathrm{pH}$ values were adjusted with diluted $\mathrm{HCl}$ and $\mathrm{NaOH}$ solutions. All the adsorption experiments were carried out at room temperature $\left(23 \pm 2{ }^{\circ} \mathrm{C}\right)$, using agitation speed $(400 \mathrm{rpm})$ for the minimum contact time required to reach the equilibrium. Adsorption of $\mathrm{Ni}^{2+}$ was studied using different weights of AC and MD prepared from Gracilaria and different concentrations of $\mathrm{Ni}^{2+}$ and initial $\mathrm{pH}$ 5.0.

\section{Equilibrium isotherm}

\section{Nickel uptake capacities and adsorption isotherm}

Adsorption equilibrium isotherms were studied using MD and AC dosages of 0.2, 0.4, $0.7,1.0$ and $0.2,0.4,0.7$ and 1.0 , respectively, per $100 \mathrm{~mL}$ of aqueous $\mathrm{Ni}^{2+}$ solutions of initial concentrations ranged from 5 to $50 \mathrm{mg} \mathrm{L}^{-1}$ for alga and $5-250 \mathrm{mg} \mathrm{L}^{-1}$ for MD and AC using initial $\mathrm{pH}$ 5.0. For these experiments, the screw-cap conical flasks were shaken at a speed of $200 \mathrm{rpm}$ and room temperature $\left(25 \pm 2{ }^{\circ} \mathrm{C}\right)$ for the required contact time. Then, the solution was filtered through a $0.45 \mu \mathrm{m}$ membrane filter. The $\mathrm{Ni}^{2+}$ uptake was calculated by the simple concentration difference methods. The amount of metal adsorbed by activated carbon was calculated from the difference between metal quantity added to the biomass and metal content of the supernatant using the following equation:

$$
q_{e}=\frac{\left(C_{0^{-}} C_{t}\right) V}{M}
$$

Where $\mathrm{q}_{\mathrm{e}}$ is the metal uptake (mg metal adsorbed per $\mathrm{g}$ adsorbent), $\mathrm{C}_{0}$ and $\mathrm{C}_{\mathrm{e}}$ are the initial and equilibrium metal concentrations in solution $\left(\mathrm{mg} \mathrm{L}^{-1}\right), \mathrm{V}$ is the volume of the solution $(\mathrm{mL})$ and $\mathrm{M}$ is the weight of activated carbon $(\mathrm{g})$. To examine between adsorbed and aqueous concentration at equilibrium, adsorption isotherm models, Langmuir and Freundlich adsorption models were used for the data ${ }^{13}$. These isotherm constants for $\mathrm{Ni}^{2+}$ are presented in Table 1. 
Table 1. Isotherm parameters obtained for biosorption of $\mathrm{Ni}$

\begin{tabular}{|c|c|c|c|c|}
\hline \multirow[t]{2}{*}{ Isotherm model } & \multicolumn{2}{|c|}{$\mathrm{AC}$} & \multicolumn{2}{|c|}{ MD } \\
\hline & $0.4 \mathrm{~g}$ & $0.6 \mathrm{~g}$ & $2.5 \mathrm{~g}$ & $3.5 \mathrm{~g}$ \\
\hline Langmuir & & & & \\
\hline $\mathrm{Q}_{\mathrm{m},} \mathrm{mg} \mathrm{g}^{-1}$ & 2.686 & 2.305 & 1.386 & 1.285 \\
\hline $\mathrm{B}, \mathrm{L} \mathrm{mg}^{-1}$ & 0.673 & 1.100 & 0.043 & 0.048 \\
\hline $\mathrm{R}^{2}$ & 0.924 & 0.993 & 0.999 & 0.999 \\
\hline Freundlich & & & & \\
\hline $1 / \mathrm{n}$ & 0.144 & 0.175 & 0.627 & 0.741 \\
\hline$\underset{\mathrm{L}, \mathrm{mg}^{-1} \mathrm{~g}_{1 / \mathrm{n}}^{-1},}{\mathrm{~K}^{-1}}$ & 1.595 & 1.322 & 0.092 & 0.075 \\
\hline $\mathrm{R}^{2}$ & 0.979 & 0.982 & 0.972 & 0.999 \\
\hline
\end{tabular}

Freundlich adsorption model

The Freundlich model ${ }^{14}$ habitually gives a better fit for adsorption from liquids and can be expressed as:

$$
\mathrm{q}_{\mathrm{e}}=\mathrm{K}_{\mathrm{f}} \cdot \mathrm{C}_{\mathrm{e}}^{1 / \mathrm{n}}
$$

In this model, the rate of adsorption is of the constants $1 / n$ and $K_{f}\left(\mathrm{Lg}^{-1}\right)$. For a good adsorbent, $0.2<1 / \mathrm{n}<0.8$ and a smaller value of $1 / \mathrm{n}$ show better adsorption and formation of rather strong bond between the adsorbate and adsorbent. Many researchers have used this model to interpret adsorption data for various systems ${ }^{15-18}$.

\section{Langmuir adsorption model}

The most widely used isotherm equation for modeling equilibrium is the Langmuir equation. It is assumed that there is a finite number of binding sites that are homogeneously shared over the adsorbent surface. These binding sites have the same adsorption of a single molecular layer and there is no interaction between adsorbed molecules. The saturated monolayer isotherm can be represented as:

$$
q_{e}=\frac{b \cdot q_{\max } C_{e}}{\left(1+b \cdot C_{e}\right)}
$$

Where $\mathrm{q}_{\mathrm{e}}$ is metal ion adsorbed $\left(\mathrm{mg} \mathrm{g}^{-1}\right), \mathrm{C}_{\mathrm{e}}$ is the equilibrium concentration $\left(\mathrm{mg} \mathrm{L}^{-1}\right)$, $\mathrm{q}_{\max }$ is the maximum adsorption capacity and $\mathrm{b}$ is an affinity constant, whereas, $\mathrm{q}_{\max }$ represents a practical limiting adsorption capacity when the surface is fully covered with metal ions and assists in comparison of adsorption performance, in cases where the adsorbent did not reach its full saturation in experiments and $b$ is constantly related to the affinity of the binding sites ${ }^{19}$.

\section{Adsorption kinetic studies}

The kinetics of adsorption describes the rate of nickel ions uptake on AC and MD prepared from Gracilaria which controls the equilibrium time. These kinetic models included the first order and second order equations.

\section{Pseudo first order model}

The pseudo first order rate expression is described by the following equation ${ }^{20}$.

$$
\mathrm{dq}_{t} / \mathrm{d}_{\mathrm{t}} /=\mathrm{k}_{1}\left(\mathrm{q}_{\mathrm{e}}-\mathrm{q}_{\mathrm{t}}\right)
$$

Where $\mathrm{q}_{\mathrm{e}}$ is copper sorbed at equilibrium per unit weigh of adsorbent $(\mathrm{mg} / \mathrm{g}) ; \mathrm{q}_{t}$ is copper sorbed $(\mathrm{mg} / \mathrm{g})$ and $\mathrm{k}_{1}$ is the rate constant $\left(\mathrm{min}^{-1}\right)$. The integrated form of Eq. (4) becomes: 


$$
\log \left(\mathrm{q}_{\mathrm{e}}-\mathrm{q}_{t}\right)=\log \left(\mathrm{q}_{\mathrm{e}}\right)-\left(\mathrm{k}_{1} / 2.303\right) \mathrm{t}
$$

A plot of $\log \left(\mathrm{q}_{\mathrm{e}}-\mathrm{q}_{t}\right)$ versus $(\mathrm{t})$ indicates a straight line of slope $\left(\mathrm{k}_{1} / 2.303\right)$ and an intercept of $\log \left(\mathrm{q}_{\mathrm{e}}\right)$. The adsorption first-order rate constants ranged between 0.013-0.071 and $0.012-0.103 \mathrm{~min}^{-1}$ for DM alga and AC, respectively (Table 2). The variation in rate should be proportional to the first power of concentration for strict surface adsorption. However, the relationship between initial solute concentration and rate of adsorption will not be linear when pore diffusion limits the adsorption process. It was observed that kinetic model fits well for the first $40 \mathrm{~min}$ and thereafter the data deviate from the theory. Thus, the model shows the initial stages where rapid adsorption occurs well but cannot be applied for the entire adsorption process. Ho and $\mathrm{McKay}^{18}$ reported that the sorption data were represented well by the Lagergren second-order model only for the rapid initial phase that occurs for a contact time of $0-30 \mathrm{~min}$. This confirms that it is not appropriate to use the Lagergren kinetic model to predict the adsorption kinetics for chromium onto dried green alga and its activated carbon for the entire sorption period. While it gave predicted $q_{\mathrm{e}}$ far from the experimental $q_{\mathrm{e}}$ for both dried green alga and activated carbon, which shows that the pseudo second-order model can be applied but is not appropriate to describe the entire process and to predict the $q_{\mathrm{e}}$.

Table 2. Parameters kinetic model for biosorption of $\mathrm{Ni}$

\begin{tabular}{cccccccc}
\hline & Parameter & \multicolumn{3}{c}{ First-order kinetic model } & \multicolumn{3}{c}{ Second- order kinetic model } \\
\hline \multirow{2}{*}{ Algae } & $\begin{array}{c}\text { Initial Ni } \\
\text { concentration, mg L }\end{array}$ & $\mathrm{K}_{2}$ & $\begin{array}{c}\mathrm{q}_{\mathrm{e}} \\
\text { (calculated ) }\end{array}$ & $\mathrm{R}^{2}$ & $\mathrm{~K}_{2}$ & $\begin{array}{c}\mathrm{q}_{\mathrm{e}} \\
\text { (calculated ) }\end{array}$ & $\mathrm{R}^{2}$ \\
\hline $0.6 \mathrm{~g}$ & 30 & 0.00 & 0.04 & 0.67 & 0.057 & 1.00 & 1.00 \\
$\mathrm{AC}$ & 50 & 0.07 & 0.03 & 0.68 & 0.014 & 1.03 & 0.99 \\
& 70 & 0.05 & 0.02 & 0.76 & 0.007 & 1.08 & 0.99 \\
$2.5 \mathrm{~g}$ & 30 & 0.01 & 0.15 & 0.92 & 0.003 & 0.99 & 1.00 \\
$\mathrm{DM}$ & 50 & 0.00 & 0.03 & 0.98 & 0.065 & 0.84 & 1.00 \\
& 70 & 0.00 & 0.02 & 0.91 & 0.004 & 0.91 & 1.00 \\
\hline
\end{tabular}

\section{Pseudo second order model}

The adsorption data also analyzed a pseudo second order $^{20}$, given by

$$
\mathrm{dq}_{\mathrm{t}} / \mathrm{d}_{\mathrm{t}}=\mathrm{K}_{2}\left(\mathrm{q}_{\mathrm{e}}-\mathrm{q}_{\mathrm{t}}\right)^{2}
$$

Where, $\mathrm{K}_{2}$ is the equilibrium rate constant $(\mathrm{g} / \mathrm{mg}$, $\min ) . \mathrm{Q}_{\mathrm{e}}$ and $\mathrm{q}_{\mathrm{t}}$ are the adsorption capacities at equilibrium at time $\mathrm{t}$. The integrated form of $\mathrm{Eq}(5)$ becomes:

This has linear form:

$$
1 /\left(\mathrm{q}_{\mathrm{e}}-\mathrm{q}_{\mathrm{t}}\right)=1 /\left(\mathrm{q}_{\mathrm{e}}\right)+\mathrm{K}_{2} \mathrm{t}
$$

$$
\mathrm{t} / \mathrm{q}_{\mathrm{t}}=1 / \mathrm{K}_{2} \cdot \mathrm{q}_{e}^{2}+\left(1 / \mathrm{q}_{\mathrm{e}}\right) \mathrm{t}
$$

A plot $\mathrm{t} / \mathrm{q}_{\mathrm{e}}$ versus $\mathrm{t}$ shows a straight line of slope $\left(1 / \mathrm{q}_{\mathrm{e}}\right)$ and an intercept of $\left(1 / \mathrm{K}_{2} \cdot \mathrm{q}_{e}^{2}\right)^{21}$. As a result of failure in applicability of pseudo second-order, the adsorption kinetics was explained by Ho and $\mathrm{McKay}{ }^{18}$ Eq. (7). The second order rate constants $K_{2}$, the calculated $q_{\mathrm{e}}$ values and correlation coefficients were reported in Table 2 . It was observed that the pseudo second-order rate constant $\left(K_{2}\right)$ decreased with increased initial concentration for both DM and its AC. The calculated $q_{\mathrm{e}}$ values agreed very well with the experimental values and the regression coefficients were above 0.99 and 1.0 for $\mathrm{AC}$ and DM, respectively, which showed that the pseudo second-order model could be applied for the entire adsorption process and confirmed of $\mathrm{Ni}^{2+}$ onto $\mathrm{DM}$ and its $\mathrm{AC}$. 


\section{Results and Discussion}

The present study shows that AC and MD prepared of red algae Gracilaria have an ability to remove $\mathrm{Ni}^{2+}$ from the contaminated water. The data obtained from this work supports the view that the $\mathrm{AC}$ is effective for the removal of $\mathrm{Ni}^{2+}$ from aqueous solution. The adsorption of metal ions is dependent on $\mathrm{AC}$ and $\mathrm{MD}$, concentration of metal ion, retention time and $\mathrm{pH}$ of the metal solution.

\section{Effect of $p H$ on adsorption}

Figure 1 shows that the biosorption of $\mathrm{Ni}^{2+}$ was increased up to $\mathrm{pH}$ 5.0. The lower uptake at higher $\mathrm{pH}$ value is probably due to the formation of anionic hydroxide complexes. Due to these lower uptakes at higher $\mathrm{pH}$ values the ligands such as carboxylate and sulfonate groups could uptake fewer metal ions ${ }^{12}$. The initial $\mathrm{pH}$ of the metal solution is an important parameter affecting adsorption of metal ions ${ }^{22}$. The effect of initial $\mathrm{pH}$ on the removal of $\mathrm{Ni}^{2+}$ using AC and MD prepared of Gracilaria was studied (Figure 1). It is clear from the removal of $\mathrm{Ni}^{2+}$ decreased with an increase in $\mathrm{pH}$ from 1.0 to 9.0 and an optimum $\mathrm{pH}$ of about 5.0 was observed. In the literature ${ }^{23}$, similar has been reported by the nature of the biosorption at different $\mathrm{pH}$. The lower uptake at higher $\mathrm{pH}$ value is probably due to the formation of anionic hydroxide complexes. So in this study, relationship between adsorption and bioreduction is discussed. When $\mathrm{pH}$ increased 1.0 to 5.0, strange adsorption algae increased, because in the case algae entered heavy metals from ligands. In $\mathrm{pH} 5.0$ reduction rate of algae is very high.

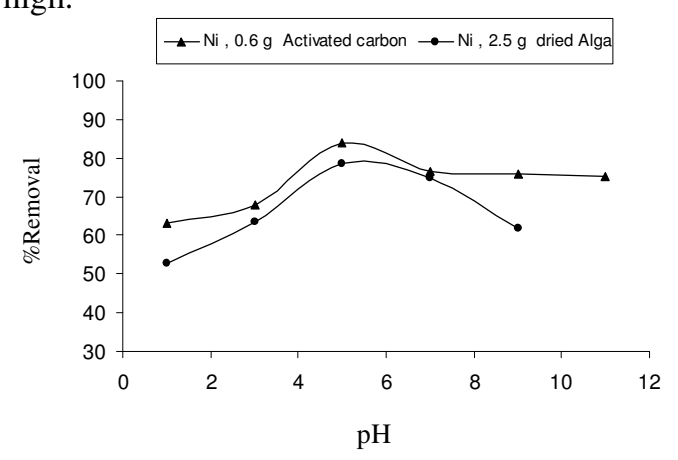

Figure 1. Effect of $\mathrm{pH}$ on adsorption of $50 \mathrm{mg} \mathrm{L}^{-1} \mathrm{Ni}$ (II) by DM and MD after $15 \mathrm{~min}$

At low and high $\mathrm{pH}$, on the other hand, $\mathrm{Ni}^{2+}$ had a higher redox potential and favored $\mathrm{Ni}(\mathrm{II})$ bioreduction $^{24}$. In addition, reductions on the biomass such as carbohydrate and protein could supply electrons for $\mathrm{Ni}(\mathrm{II})$ bioreduction, with partial release of soluble organics or final oxidized product ${ }^{25}$.

\section{Effect of metal ion concentration on adsorption}

The initial concentration of metal ion provides an important driving force to overcome all mass transfer resistances of metal ions between the aqueous and solid phases ${ }^{26}$. Figure 2 represented the effect of different initial concentrations of $\mathrm{Ni}^{2+}\left(30-70 \mathrm{mg} \mathrm{L}^{-1)}\right.$ on adsorption $\mathrm{Ni}^{2+}$ using marine algae Gracilaria (red algae) and its $\mathrm{AC}$ and MD. The results show the increase in initial concentration of $\mathrm{Ni}^{2+}$ which led to a decrease in the percentage of removal for both adsorbents due to saturation of the adsorption sites on adsorbents, the maximum uptake for nickel with initial concentration, 30 and $40 \mathrm{mg} \mathrm{L}^{-1}$ at $\mathrm{pH} 5.0$ and $2.5 \mathrm{~g} \mathrm{MD}$ and $0.6 \mathrm{~g}$ AC prepared in Gracilaria were obtained as $83.55 \%$ and $99.04 \%$, respectively. 


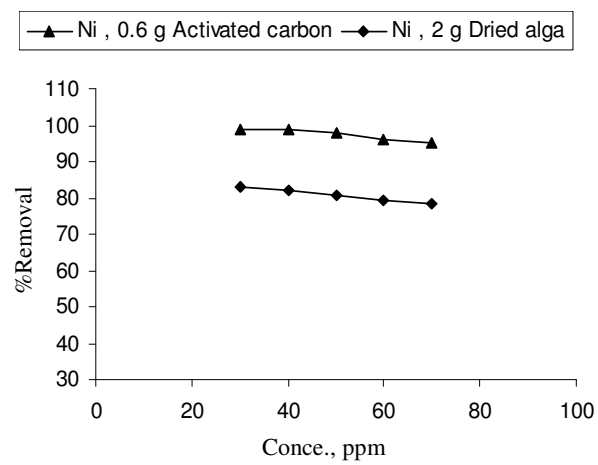

Figure 2. The effect of initial concentration of metal ion on the percentage of removal of $\mathrm{Ni}(\mathrm{II})$ at $\mathrm{pH} 5$ and room temperature using $\mathrm{MD}$ and $\mathrm{AC}$

\section{Effect of retention time}

Figure 3 indicates that removal ability increased with increasing contact time and concentrated heavy metals before equilibrium reached. Other limits such as dose of adsorbent, $\mathrm{pH}$ of solution and initial concentration were kept optimum. While temperature was kept at $\left(23 \pm 2{ }^{\circ} \mathrm{C}\right)$ it can be seen from Figure 3 that $\mathrm{Ni}$ removal efficiency increased when contact time was increased from $15 \mathrm{~min}$. Optimum contact time for both adsorbents was found to be $15 \mathrm{~min}$. In previous literature, similar has been reported by the evaluation of the MD Gracilaria corticata for the adsorption of $\mathrm{Cu}(\mathrm{II})$ from wastewater in a packed column reported ${ }^{27}$.

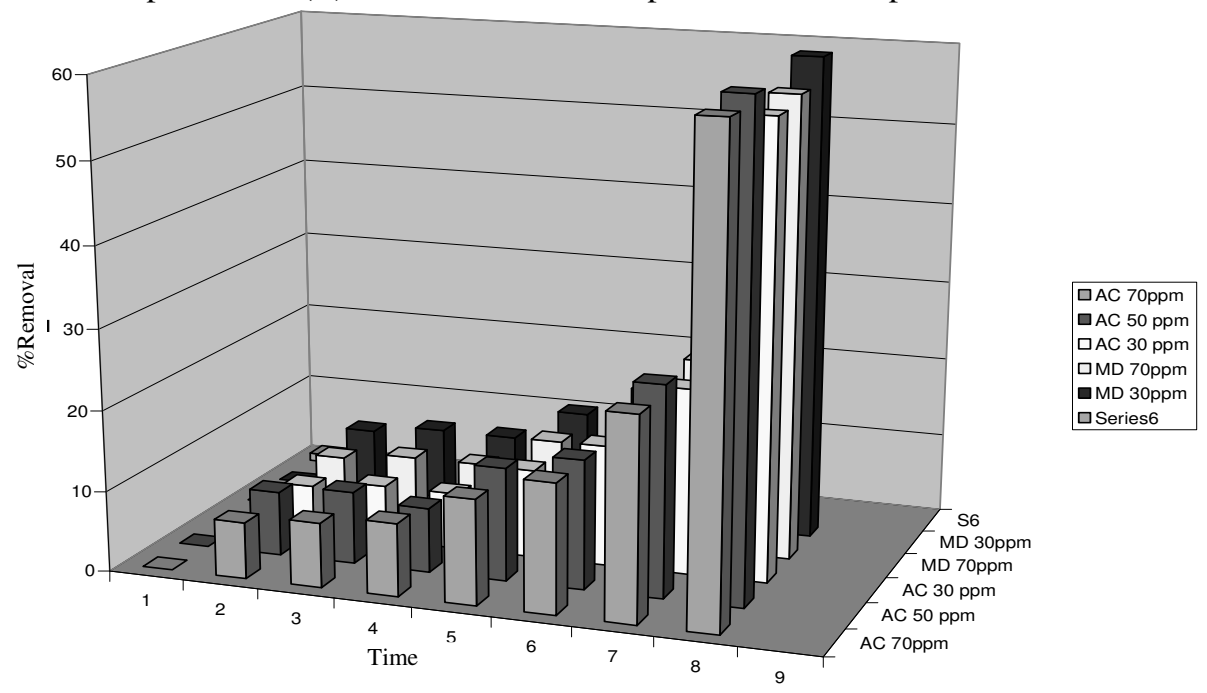

Figure 3. The effect of time on the percentage of removal of $\mathrm{Ni}(\mathrm{II})$ at $\mathrm{pH} 5$ and room temperature using DM and $\mathrm{AC}$

\section{Effect of adsorbent dose on adsorption}

The initial concentration of metal ion provides an important driving force to overcome all mass transfer resistances of metal ions between the aqueous and solid phases ${ }^{26}$. The results show that the equilibrium concentration of $\mathrm{Ni}^{2+}$ increased with an increasing adsorbate concentration. It showed that the increase in initial concentration of $\mathrm{Ni}^{2+}$ led to a decrease in 
the percentage of removal for both adsorbents. When initial $\mathrm{Ni}^{2+}$ concentrations increased from 0.2 to $3.5 \mathrm{~g}$, the removal percentages decreased from 66 to $45 \%$ for MD and when initial chromium concentrations changed from 5 to $250 \mathrm{mg} \mathrm{g}^{-1}$, the percentage of removals was decreased from 100 to $90 \%$ for the AC. This was due to the saturation of the sorption sites on adsorbents ${ }^{28-29}$.

\section{Adsorption isotherm}

Adsorption isotherms are important for describing how adsorbate will interact with an adsorbent and are critical in the use of adsorbent. Equilibrium studies in adsorption isotherm are characterized by certain constants whose values express the surface properties and affinity of the adsorbent. Equilibrium between adsorbent and adsorbate was described by adsorption isotherms, usually the ratio between the quantity adsorbed and the remaining in the solution at a fixed temperature $\left(23 \pm 2{ }^{\circ} \mathrm{C}\right)$, at equilibrium. To study the adsorption isotherm, two models were analyzed.

\section{Langmuir and Freundlich isotherms}

The Langmuir adsorption isotherm is the most widely applied adsorption isotherm. A basic assumption of the Langmuir theory is that adsorption takes place at specific homogeneous sites within the adsorbent. The applicability of the empirical Freundlich isotherm was also analyzed based on the adsorption on heterogeneous surface, using the same set of experimental data of dried red and MD and its AC. The isotherm experimental results showed the data could be well modeled according to the Langmuir adsorption isotherm. The Langmuir constant $\left(\mathrm{q}_{\max }\right)$ is dependent on experimental conditions such as solution $\mathrm{pH}$.

Another importance in evaluating adsorbent performance is the initial gradient of the adsorption isotherm, since it indicates the adsorbent affinity at low metal concentrations. In the Langmuir equation, this initial gradient corresponds to the affinity constant (b). As we can see from Table 1 data could be well modeled according to the Langmuir, adsorption isotherm. In previous investigation, similar method with DM Gracilaria for the biosorption of $\mathrm{Ni}(\mathrm{II})$ has been reported ${ }^{28}$.

\section{Kinetic modeling}

The Legergren first order rate constant $\left(\mathrm{k}_{1, \text { ads }}\right)$ and $\mathrm{q}_{\mathrm{e}}$ determined from the model indicated that this model failed to estimate $\mathrm{q}_{\mathrm{e}}$ since the experimental values of $\mathrm{q}_{\mathrm{e}}$ differed from those estimated in Table 2. Subsequently, the rate of uptake of $\mathrm{Ni}^{2+}$ onto the biomass increased quickly to $15 \mathrm{~min}$ and no further adsorption was observed beyond this period. The $\mathrm{Ni}^{2+}$ uptake by the biosorbents was best described by pseudo second-order rate model. The pseudo second order model is based on the supposition that adsorption follows a second-order which means the rate of occupation of adsorption sites is proportional to the squares of number of unoccupied sites ${ }^{6,23}$. Previous literature for the evaluation of the AC prepared from the algae Gracilaria for the adsorption of $\mathrm{Cu}(\mathrm{II})$ it has been observed that the adsorption follows second order kinetics reported ${ }^{29}$.

These isotherm constants for $\mathrm{Ni}^{2+}$ are presented in Table 2 Subsequently, the rate of uptake of $\mathrm{Ni}^{2+}$ onto the biomass increased quickly till $15 \mathrm{~min}$ and no further meaningful adsorption was observed beyond this period. The nickel(II) uptake by the biosorbents was best described by pseudo second order rate model. The pseudo second order model is based on the supposition that biosorption follows a second order mechanism which means that the rate of occupation of adsorption sites is proportional to the squares of number unoccupied sites ${ }^{30}$. 


\section{Relationship between bioreduction and adsorption of $\mathrm{Ni}(\mathrm{II})$}

In order to study the effect of salinity and real wastewater on the capability of the alga Gracilaria and its developed AC to adsorb $\mathrm{Ni}^{2+}$ from its aqueous solution, removal studies were achieved using synthetic seawater, natural seawater and real wastewater. A near $100 \%$ removal of toxic nickel from synthetic seawater, natural seawater and wastewater was detected for activated carbon developed from Gracilaria. Moreover, the maximum adsorption capacities were not changed by the changing of the type of chromium solution. The presence of salt had no effect on the adsorption of $\mathrm{Ni}^{2+}$ on both adsorbents, which leads to deduce that there was no interaction between the salt and the surface of the adsorbent nor the salt and the solute $(\mathrm{Ni})$. In addition, the high concentration of $\mathrm{Ni}^{2+}$ ions may make them more preferable to be absorbed by the adsorbents. On the other hand the real wastewater may contain very low concentrations from several metal ions that will not have much effect on the removal percentage of nickel ions. These results indicate that the two sorbents MD and AC of Gracilaria are applicable material for removal of $\mathrm{Ni}^{2+}$ from different types of aqueous solutions including wastewater.

\section{Conclusion}

1. In this research two methods used in the investigation of the batch removal of $\mathrm{Ni}^{2+}$ from aqueous solution, and wastewater using marine dried (MD) red algae Gracilaria, and its activated carbon (AC).

2. A suitable indigenous $\mathrm{MD}$ and its developed $\mathrm{AC}$ have been identified as effective adsorbents to remove $\mathrm{Ni}^{2+}$ ions from different types of aqueous solutions. The adsorption kinetic data can be described by the second-order kinetic models.

3. The adsorption capacity is related to the $\mathrm{pH}$ of solution and $\mathrm{pH} 5.0$ is optimal. Furthermore, the equilibrium data of adsorption are in good agreement with the Langmuir's model. The MD and its AC are inexpensive effective adsorbents for the removal of $\mathrm{Ni}^{2+}$ ions from aqueous solutions.

3. The AC developed from MD alga biomass exhibited high biosorption capacity. The adsorption of $\mathrm{Ni}^{2+}$ was found to be $\mathrm{pH}$ dependent and maximum removal was observed at $\mathrm{pH}$ 5.0. The kinetics studies showed that both Gracilaria and its AC have poor fit with pseudo first-order kinetic equation while they have a good agreement with the pseudo second-order kinetic equation. Moreover, the intra-particle-diffusion was also investigated and the adsorption process was found to be controlled by the film diffusion at lower concentrations of the adsorbate and shifted to particle diffusion at high concentration.

4. The maximum efficiencies of $\mathrm{Ni}^{2+}$ removal were $83.55 \%$ and $99.04 \%$ for $\mathrm{MD}$ and $\mathrm{AC}$ developed from it, respectively.

5. We conclude that absorption by AC is higher than the MD red algae.

6. This process is environment friendly and reduces the huge amount of indiscriminate effluent discharges around the small industry concerns. It may provide an affordable technology for small and medium-scale industry.

\section{Acknowledgment}

The authors wish to thank Mr. Dr. Marandi from Department of Chemical Engineering, North Tehran Branch, Azad Islamic University, Iran. 


\section{References}

1. Padilla A P and Tavani E L, Desalination, 1999, 126, 219-226.

2. Yabe M J S and Oliveira E De, Adv Environ Res., 2003, 7, 263-272.

3. Oubagaranadin J U K, Sathyamurthy N and Murthy Z V P, J Hazard Mater, 2007, 142, 165-174.

4. $\quad$ Regime H S, Viera F and Volesky B, Int Microbiol., 2000, 3, 17-24.

5. Mehta S K and Gaur J P, Rev Biotech., 2005, 25, 113-152.

6. Karthikeyan S, Balasubramanian R and Lyer C S P, Bioresource Techn., 2007, 98(2), 452-455.

7. Goswami S and Ghosh U C, Water SA., 2005, 31(4), 597-602.

8. Davis T A, Llanes F, Volesky B, Diaz-Pulido G, McCook L and Mucci A, Appl Biochem Biotech., 2003, 110, 75-90

9. Babel S and Kurmiawan T A, J Hazard Mater, 2003, 97, 219-243.

10. Fourest E and Roux J C, Appl Microbial Biotechnol., 1992, 37, 399-403.

11. Abdelwahab O, El Nemr A, El-Sikaily A and Khaled A, Chem Ecol., 2006, 22, 253-266.

12. Kapoor A, Vireraghavan T and Cullimore D R, Biore Tech., 1999, 70, 95-104.

13. Langmuir I, J Am Chem Soc., 1916, 38, 2221.

14. Freundlich H M F, Uber die adsorption in losungen, Zeitschrift fur Physikalische Chemie., 1906, 57, p.385-470.

15. Padmesh T V N, Vijayaraghavan K, Sekaran G and Velan M, Chem Eng J., 2006, 122, 55-63.

16. Kundu S and Gupta A K, Chem Eng J., 2006, 122(1-2), 93-106.

17. Golder A K, Samanta A N and Ray S, Chem Eng J., 2006, 122(1-2), 107-115.

18. Ho Y S and McKay G, Chem Eng J., 1998, 70, 115-124.

19. Matheickal J T and Yu Q, Biores Technol., 1998, 69, 223-229.

20. Ho Y S and McKay G, Process Biochem., 1999, 34(5), 451-465.

21. Ag Y and Aktay Y, Biochem Eng., 2002, 12, 143-153.

22. Esmaeili A, Ghassemi S and Rustaiyan A, J Marine Sci Technol., 2010, 18(4), 587-592

23. Kalyani S, Srinivasa Rao P and Krishnaiah A, Chemosphere, 2004, 57(9), 1225-1229.

24. Kratochvil D, Pimentel P and Volesky B, Environ Sci Technol., 1998, 32, 2693-2698.

25. Park D, Yun Y-S and Park J M, Environ Sci Technol., 2004, 38(18), 4860-4864.

26. Malkoc E, J Hazard Mater., 2006, 138, 142-151.

27. Esmaeili A, Beirami P, Rustaiyan A, Rafiei F, Ghasemi S and Assadian F, J Mar Environ Eng., 2008, 9, 65-73.

28. Esmaeili A and Ghasemi S, World Appli Sci J., 2009, 6(4), 515-518.

29. Esmaeili A. Ghasemi S and Rustaiyan A, African J Biotechnol., 2008, 7(12), 2034-2037.

28. Nuhoglu Y and Oguz E, Process Biochem., 2003, 38, 1627-1631.

29. Malkoc E and Nuhoglu Y, Fresenius Environ Bull., 2003, 12(4), 376-381.

30. Karthikeyan S, Balasubramanian R and Iyer C S P, Bioresource Tech., 2007, 98(2), 452-455. 


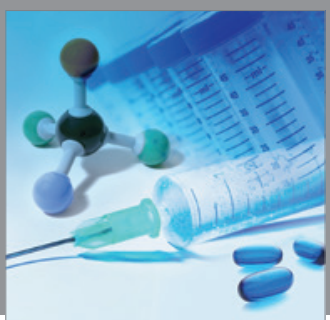

International Journal of

Medicinal Chemistry

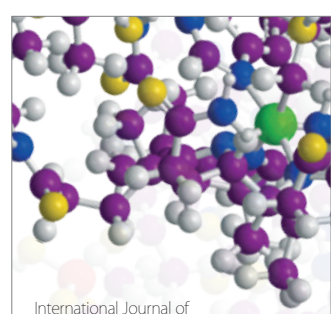

Carbohydrate Chemistry

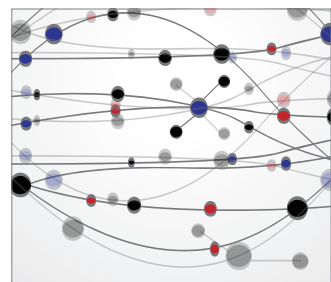

The Scientific World Journal
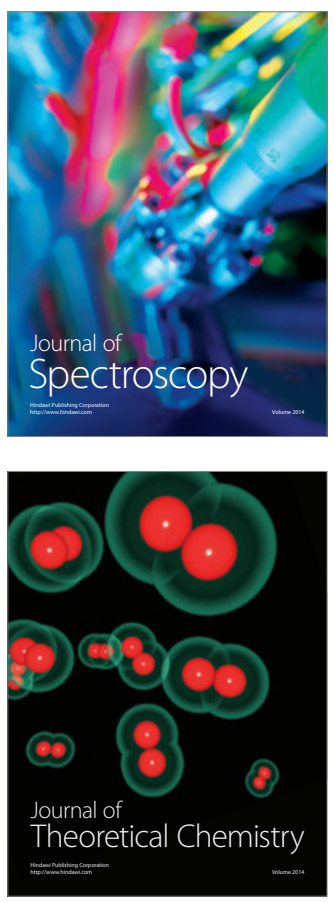
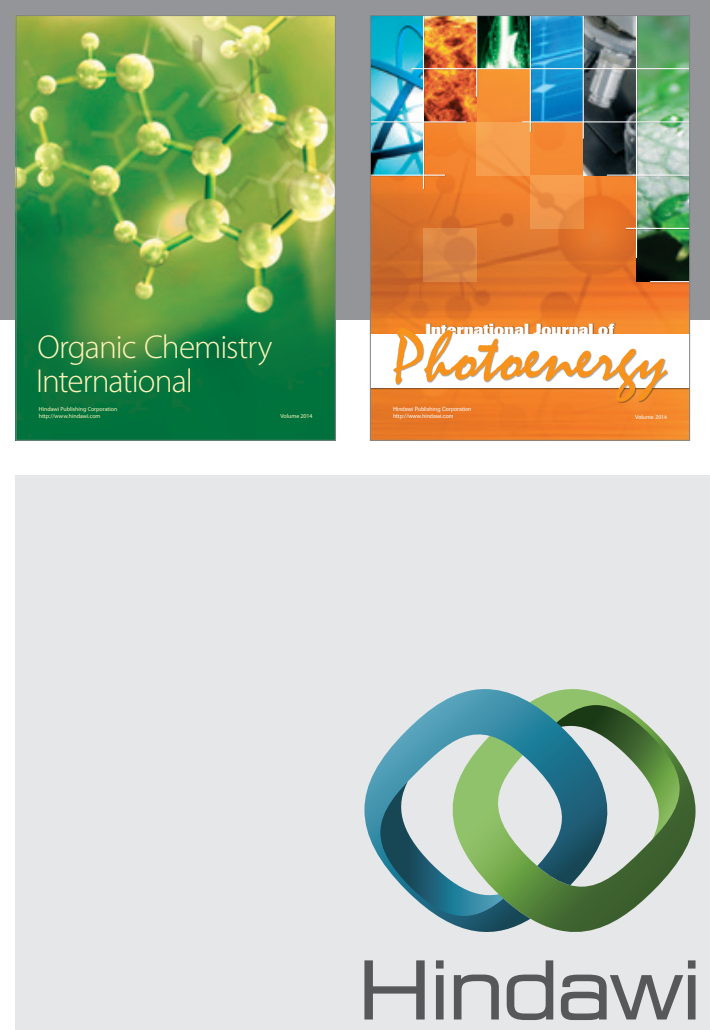

Submit your manuscripts at

http://www.hindawi.com
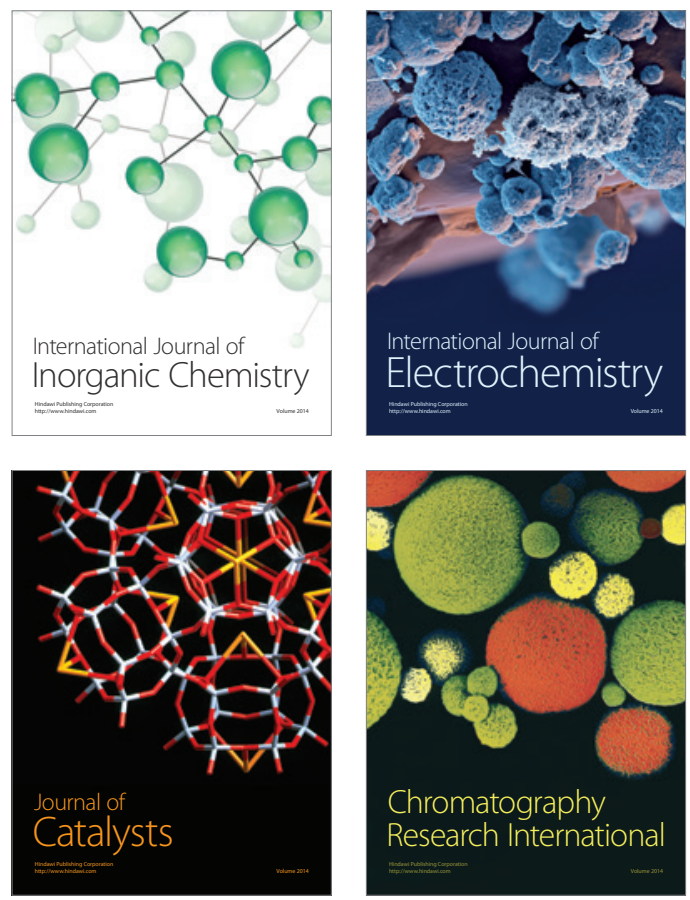
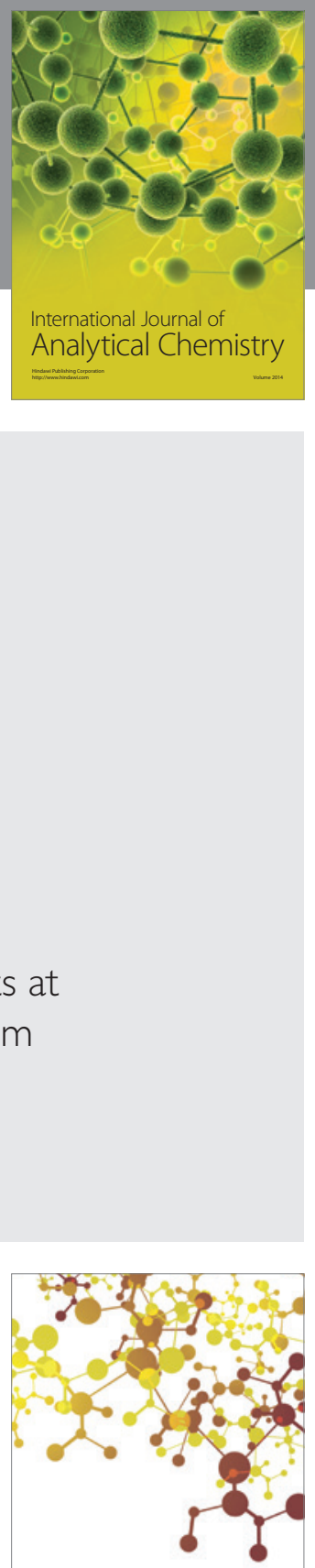

Journal of

Applied Chemistry
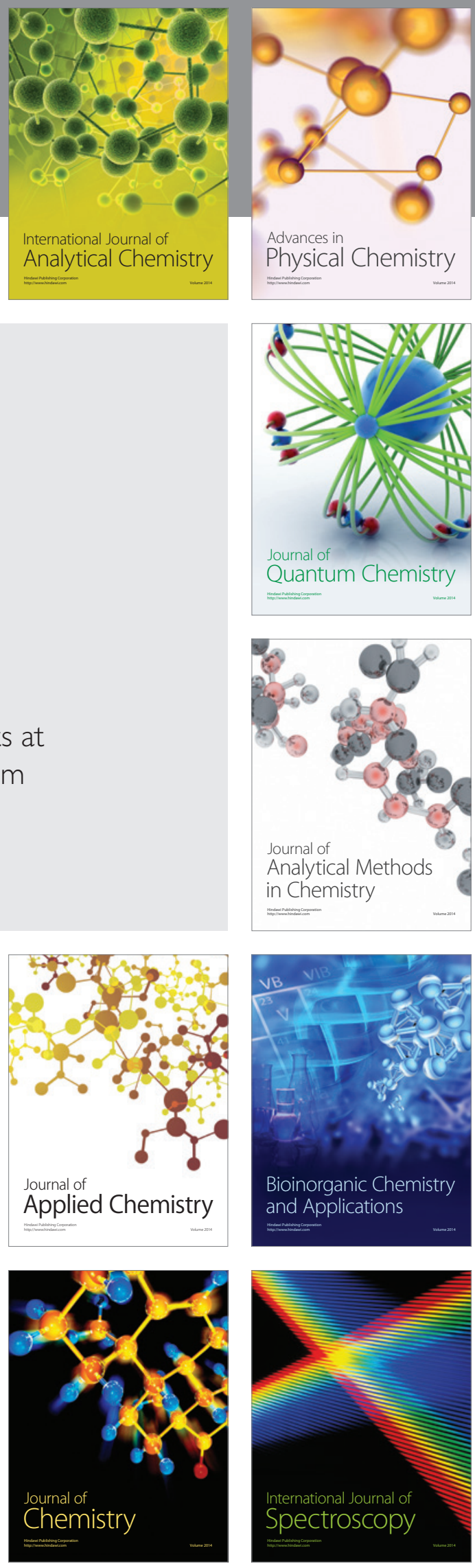